\title{
Learning the Hard Way: Imprinting Can Enhance Enforced Shifts in Habitat Choice
}

\author{
Niclas Vallin and Anna Qvarnström \\ Animal Ecology, Department of Ecology and Genetics, Evolutionary Biology Centre, Uppsala University, Norbyvägen 18D, \\ 75236 Uppsala, Sweden \\ Correspondence should be addressed to Niclas Vallin, niclas.vallin@ebc.uu.se
}

Received 29 June 2011; Revised 30 August 2011; Accepted 16 September 2011

Academic Editor: Zachariah Gompert

Copyright ( ${ }^{2} 2011$ N. Vallin and A. Qvarnström. This is an open access article distributed under the Creative Commons Attribution License, which permits unrestricted use, distribution, and reproduction in any medium, provided the original work is properly cited.

\begin{abstract}
We investigated the potential importance of learning in habitat choice within a young hybrid zone of two closely related species of birds. Pied flycatchers (Ficedula hypoleuca) are being excluded from deciduous habitats into a mixed forest type by collared flycatchers (F. albicollis). We investigated whether this enforced habitat shift influenced reproductive isolation between the two species, and, by cross-fostering nestlings, we tested whether learning may lead to a corresponding shift in habitat choice in consecutive generations. Our results show that the majority of the recruits, even if translocated across different habitat types, return to breed in the area where they were fostered. As male pied flycatchers were more likely to hybridize in the originally preferred habitat, we argue that early imprinting on an alternate habitat can play an important role in increasing reproductive isolation and facilitate regional coexistence between species experiencing secondary contact.
\end{abstract}

\section{Introduction}

In the past decade, a revived interest in the role of adaptation to different environments in speciation, that is, ecological speciation, has emerged [1-4]. One important mechanism underlying ecological speciation is the buildup of reproductive isolation caused by habitat segregation (i.e., habitat isolation, e.g., [5]). Theoretical models of sympatric speciation generally include disruptive selection in resource use, which by extension can lead to differences in habitat choice and thereby reduced interbreeding [6-12]. Adaptive differences in habitat use can moreover evolve among allopatric populations, resulting in habitat isolation at secondary contact $[13,14]$. Habitat isolation between species can also evolve at secondary contact, where reinforcement and competition are plausible drivers [15].

One factor suggested to potentially both promote and reduce the likelihood of ecological speciation is phenotypic plasticity [16]. Phenotypic plasticity can be defined as changes in an individual's behavior, morphology, and physiology directly induced by different environmental conditions [17-19] and is adaptive if individuals showing a plastic response have higher fitness than those that do not. In particular, moderate levels of plasticity appear to enhance evolution in novel environments by placing populations under directional selection towards new adaptive peaks [17]. Thibert-Plante and Hendry [16] found that plasticity also could counteract the buildup of reproductive isolation between populations after colonization of new environments. This is because selection against immigrants can be mitigated if dispersal occurs before the plastic adjustment to the environment. Thus, plasticity may have a large impact on the speciation process. Still, an underlying assumption in many models on the evolution of habitat isolation is that habitat choice is a genetically determined trait. However, learned habitat choice occurs in several animal species [20] and may, together with other forms of learning (e.g., sexual imprinting; [21]), be of importance in relation to speciation [6, 16, 18, 22, 23]. Beltman and Metz [24] found that speciation is more likely to occur through a learned than through a genetic habitat preference, unless the cost of learning is high, which, together with recent empirical findings (reviewed by $[20,25]$ ), indicates that the relevance of learning in speciation may have been underestimated. 
In this study, we use a combination of long-term breeding data and an experimental approach to investigate mechanisms behind divergence in habitat choice within a young hybrid zone of two closely related, hybridizing, and competing species of Ficedula flycatchers. Collared (Ficedula albicollis) and pied (F. hypoleuca) flycatchers cooccur in central and eastern Europe and on the Baltic isles of Öland and Gotland in Sweden [26]. The two species started to diverge 1-2 million years ago and were probably periodically isolated in separate glacial refuges during the Pleistocene, before expanding their breeding ranges northward [27]. Both species are migratory and winter in Africa in separated, but probably slightly overlapping, areas [28]. Pied flycatchers migrate along the Iberian Peninsula and winter in western to central Africa, and collared flycatchers winter in southeastern Africa, taking a more eastern migration route through Italy or further east $[28,29]$. Males of the two species compete fiercely over natural tree holes or nest boxes after arrival at the breeding grounds in Europe [30,31], and the two species overlap in timing of breeding [32] and feeding habits [33] suggesting strong interspecific competition. Collared flycatcher offspring have a higher growth potential under favorable environmental conditions [32, 34], but pied flycatchers are relatively more robust to harsh environments and towards the seasonal decline in food availability, providing them an opportunity to prolong coexistence with the otherwise more aggressive collared flycatchers [32, 34]. Pied flycatchers prefer to breed in deciduous forests [29] but are often found in coniferous forests on Öland [35]. The proportion of deciduous trees in pied flycatcher territories has declined in recent years as the number of collared flycatchers has increased [36] suggesting that competitionmediated habitat segregation is currently taking place. Here, we investigate potential mechanisms enhancing divergent habitat choice in these two ecologically similar Ficedula flycatcher species. More specifically, we test the role of learning in maintaining initially enforced shifts in habitat choice.

\section{Material and Methods}

2.1. Study System. Collared flycatchers started to colonize Öland, where pied flycatchers were already present, in the late 1950s-early 1960s, and since then the relative proportion of pied flycatchers has quickly declined in the most favorable breeding sites [32]. There is species assortative mating in the mixed study population on Öland, but $5 \%$ of all pairs are heterospecific, and approximately $2-7 \%$ of the breeding flycatchers in different mixed populations are hybrids (reviewed in [26]). Male hybrids have lowered fitness, mainly due to disadvantages in competition over mates, while female hybrids are sterile in accordance with Haldane's rule [37]. On Öland, the two species breed in 21 nest-box areas situated across the island (Figure 1). The landscape on Öland is characterized by a limestone plain covered by a thin soil layer. The southern part of the island is dominated by agricultural land, the middle part by deciduous forest, and the very north of the island contains mixed or coniferous dominated forests (Figure 1). Females lay one egg each day, and every nest box

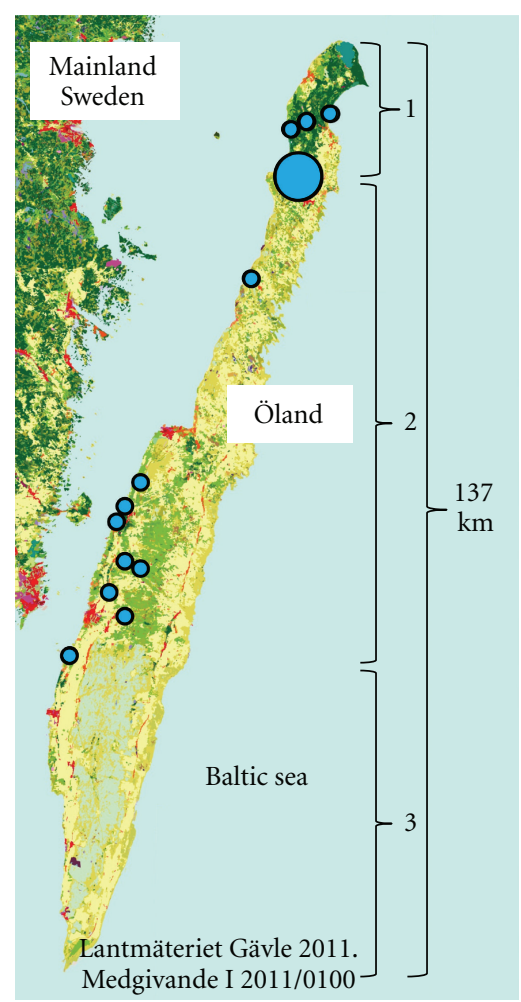

FIgURE 1: Landscape types $(1=$ mixed or coniferous forest, $2=$ deciduous forest, 3 = agricultural land) and distribution of Ficedula flycatcher nest-box areas (blue circles) on the Swedish island of Öland. The large circle represents nine nest-box areas surrounding the town of Löttorp where collared flycatchers started to colonize the island (and where pied flycatchers were already present) in the late 1950s-early 1960s. Collared flycatchers now outnumber pied flycatchers in this area ( $\sim 90 \%$ collared flycatchers). The relative proportion of collared flycatchers gradually declines southward. Two of the nest-box areas in the north of the island are dominated by coniferous forest and so far only inhabited by pied flycatchers.

is monitored every third day to assess the starting day of egg laying. All breeding birds and their offspring are marked individually with numbered metal rings, and a small amount of blood is sampled for genetic analyses. Yearly records are kept on onset of egg laying, clutch size, hatching date, hatching, and fledging success. Morphological characters are measured in a standardized manner [30]. Adult females are caught when incubating the eggs, and adult males are caught when feeding the nestlings. Nestlings are weighed at day 7 and 13 , and tarsus length is measured at day 13, a couple of days before fledging. Monitoring of the nest boxes has been performed during the periods 1981-1985 and from 2002 onwards. The breeding habitat was measured as the abundance of each tree species $360^{\circ}$ around the nest boxes using a "relascope" (see [35]), which is a scale held at a fixed distance from the eye. By looking through an opening in the scale, individual trees are assigned into three categories based on trunk size and distance from the nest box. To investigate whether the habitat choice of pied flycatchers influences the risk of hybridization, we compared the habitat composition of con- and heterospecifically paired male pied flycatchers. 


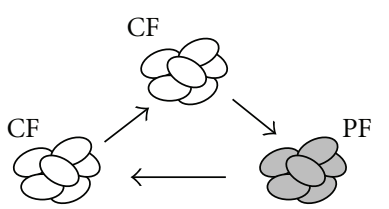

(i)

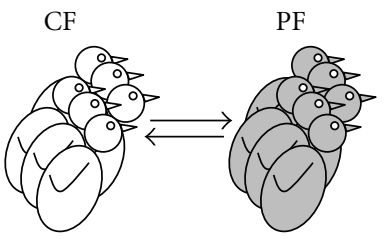

(i)

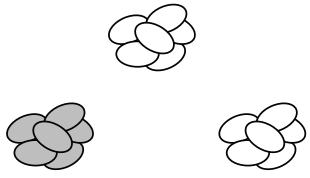

(ii)

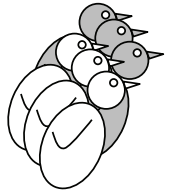

(ii)

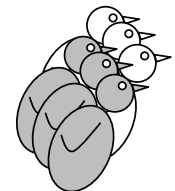

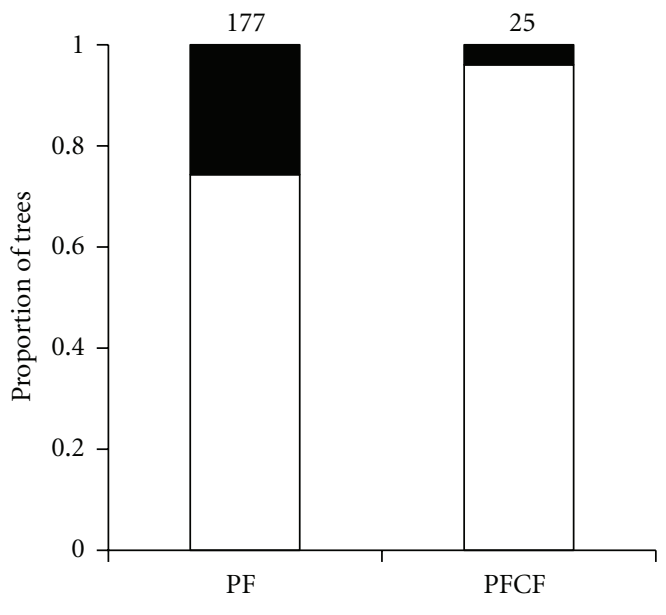

Coniferous

$\square$ Deciduous

Figure 3: Proportion of coniferous versus deciduous tree species in the breeding territories of pied flycatcher pairs (PF) compared to the breeding territories of male pied flycatchers paired to a female collared flycatcher (PFCF) on the Swedish island of Öland, 20022010. Male pied flycatchers have a lower risk of hybridizing in habitats with coniferous forest. Sample sizes are given above the bars.

2.2. Cross-Fostering Experiment. We investigated the role of early learning in breeding habitat choice by comparing patterns of recruitment of birds that had been reared by foster parents. To increase the likelihood of recruiting nestlings reared in a new environment, we swapped complete clutches of eggs three days before the expected hatching date between different nests; the genetic parents nest (i.e., the nest of origin) and the foster parents nest (i.e., the nest of fledging). The cross-fostering experiment was performed between three nests with the same clutch size and date of egg laying: from collared flycatcher to collared flycatcher (to be used as a control in another study; Vallin et al. unpublished manuscript), from collared flycatcher to pied flycatcher with the pied flycatcher eggs thereafter being translocated back to the original collared flycatcher nest (Figure 2(a)). In addition, we also included recruits stemming from earlier cross-fostering experiments in our analysis. In these crossfostering experiments, broods with coinciding hatching dates were split in half and nestlings were swapped between nests at the age of three days (e.g., [34, 38], Figure 2(b)). In one study [32], cross-fostering was performed with an additional brood size manipulation to simulate good and harsh environments. All nestlings were individually marked by clipping their toenails to enable individual measurements of growth and to ensure correct identification of species and nest of origin. JMP 8 (SAS Institute, Cary, NC, USA) was used to analyze the data.

\section{Results}

Pied flycatchers are currently being excluded from the preferred deciduous habitats on Öland, and we compared how the general habitat composition (proportion of deciduous trees) influenced the chance of pairing with a con- or heterospecific female among male pied flycatchers using a generalized linear model adjusted for overdispersion with binomial errors and a logit link. We found that hybridizing male pied flycatchers had a significantly higher proportion of deciduous trees in their breeding territories than males paired to a conspecific female $\left(N=202, d f=1, \chi^{2}=14.19\right.$, $P<0.001$, Figure 3).

We used cross fostering experiments to investigate whether learning may influence habitat choice. In total, we included 264 nests subject to cross-fostering between the years 2002-2009 in these analyses: 96 nests where eggs were translocated and 168 nests where nestlings were crossfostered. Many of the study plots are located far apart (maximum distance $\sim 85000 \mathrm{~m}$, Figure 1 ) with pronounced differences in habitat composition [32]. We compared the general habitat composition (proportion of deciduous trees) among the pied and collared flycatcher territories that nestlings were swapped between using a generalized linear model adjusted for overdispersion with binomial errors and a logit link. We found that the habitat composition of pied and collared flycatchers included in the experiment was significantly different $\left(N=48, \chi^{2}=10.62\right.$, $d f=1, P=0.001$ ), with a higher proportion of coniferous trees in pied flycatcher territories (Figure 4). Thus, in general nestlings that were swapped into a new nest experienced a different rearing environment than they would have done if they had been reared by their genetic parents.

We identified 49 recruits stemming from the experimental nests. The average recruitment rate was $4.3 \%$ (40 recruits 


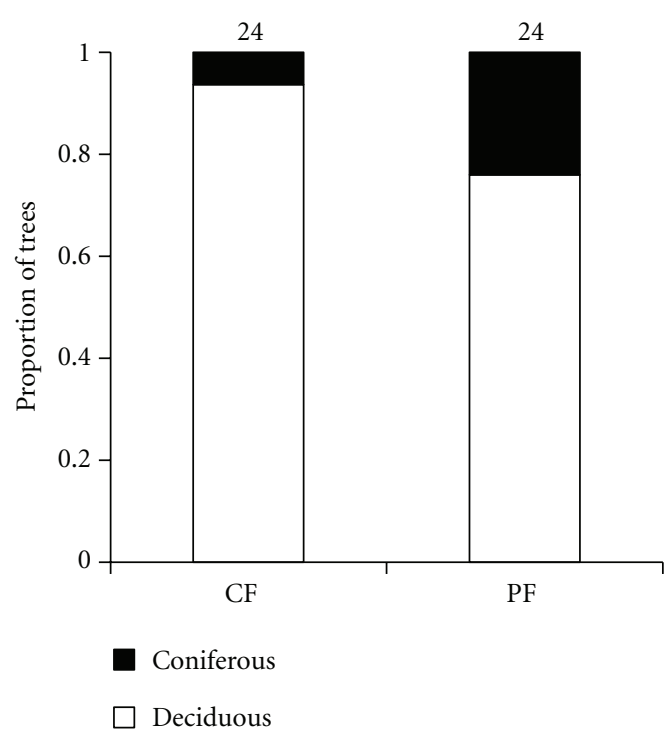

Figure 4: Proportion of coniferous versus deciduous tree species in the breeding territories of collared flycatchers (CF) and pied flycatchers $(\mathrm{PF})$ subject to experimental cross- fostering of their nestlings on Öland, Sweden, 2002-2009. The territories of collared flycatchers had a relatively higher proportion of deciduous trees as compared to the territories of pied flycatchers. Sample sizes are given above the bars.

from 933 confirmed fledged offspring, i.e., data on fledging success were missing from the nests of 9 recruits). There was no significant difference in recruitment between nests depending on whether eggs or nestlings were swapped $(N=$ 218, $\left.\chi^{2}=0.704, d f=1, P=0.40\right)$, and no significant difference in recruitment between the species $(N=218$, $\left.\chi^{2}=0.386, d f=1, P=0.53\right)$; pied flycatchers recruited 21 juveniles from a total of 431 confirmed fledged offspring and collared flycatchers recruited 19 juveniles from a total of 502 confirmed fledged offspring. Of the 49 recruits from the cross-fostering experiments, $30(61.2 \%)$ were recruits that had been swapped into a different rearing nest than the one attended by their genetic parents, and 24 of those were recruits from swaps between pied and collared flycatchers: 20 collared flycatchers ( 11 males and 9 females) and 4 pied flycatchers (1 male and 3 females). Thus, collared flycatchers had a significantly higher chance of recruiting back to the population compared to pied flycatchers when being raised by foster parents (two-tailed Fisher's exact test: $N=24$, $P=0.03)$.

We applied a matched pairs $t$-test to test whether nestlings cross-fostered between pied and collared flycatchers returned closer to the breeding site of their genetic parents or to the breeding site of their foster parents. GPS coordinates (Swedish grid system RT90) of the nest-box locations were taken and the Euclidean distance in meters between them calculated using Pythagoras' formula.

The distance between the nest where the recruits returned to breed and the nest of the foster parents was significantly shorter than the distance between the nest where they bred as recruited and the nest of origin (mean difference $=21732 \mathrm{~m}, N=24, t=3,92722, d f=23$,

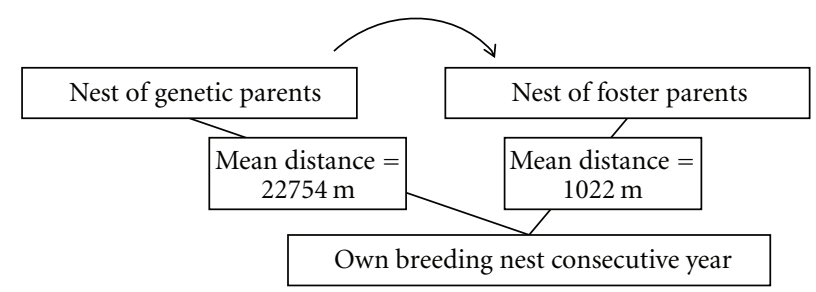

FIGURE 5: Yearling birds recruited from cross-fostering experiments between pied and collared flycatchers on the Swedish island of Öland 2002-2009 subsequently settled to breed significantly closer to their foster parents than to their genetic parents.

$P<0.001)$. The mean distance between the foster parents nest and the nest where the recruit subsequently settled was 1022 meters $(N=24$, range $=33-4256 \mathrm{~m}$, se $=247 \mathrm{~m}$, Figure 5), and the mean distance between the genetic parents nest and the nest of recruitment was 22754 meters (range $=$ $130-64481 \mathrm{~m}$, se $=5413 \mathrm{~m}$, Figure 5).

Lastly, we tested whether recruited offspring that had been translocated between habitat types returned to breed in a habitat different from their genetic parents. The pied flycatcher recruits had all been swapped between different nestbox areas and had a significantly higher mean proportion of deciduous trees in their breeding territory as compared to their genetic parents (two-tailed Fisher's exact test, $N=8$, $P=0.009$, Figure 6(a)). Similarly, an analysis with a subset of collard flycatcher recruits that had been swapped between different nest-box areas revealed that also juvenile collared flycatchers shifted their breeding habitat choice when they had been reared in a different environment as compared to their genetic parents (two-tailed Fisher's exact test, $N=28$, $P=0.0240$, Figure 6(b)).

\section{Discussion}

Pied flycatchers are currently being rapidly excluded from their preferred deciduous habitats on Öland and are instead increasingly found breeding in mixed or coniferous forests $[32,36]$. We tested if the breeding habitat of male pied flycatchers influenced the risk of hybridizing and found that male pied flycatchers were more likely to pair with a heterospecific female in deciduous habitats, that is, the observed shift in habitat occupancy increases premating isolation between the species. We investigated whether learning may speed up segregation in habitat choice. By cross-fostering nestling Ficedula flycatchers, we found that the recruits, that is, one-year old birds returning to breed themselves, settled closer to the territory of their foster parents than to the territory of their genetic parents (Figure 5). In fact, the majority of the recruits, even if translocated into a different habitat type, returned as adults to breed in the same woodlot as they were fostered into. A similar pattern was found for both species but the comparatively low proportion of pied flycatchers returning to breed as adults after being raised by foster parents ( 4 pied flycatchers versus 20 collared flycatchers) means that we cannot investigate if there is a difference in the strength of learned habitat choice between the two species. The difference in recruitment per se is likely 


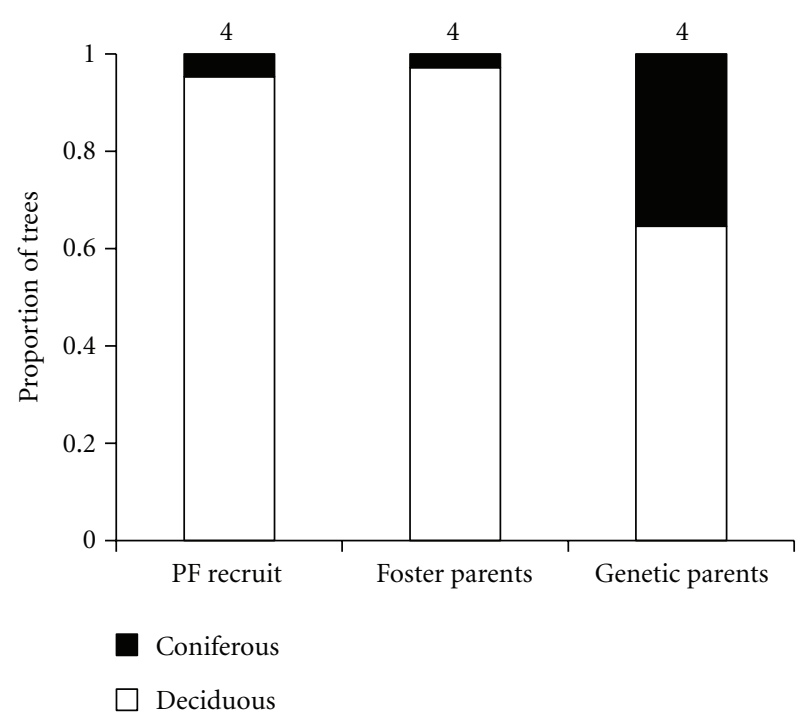

(a)

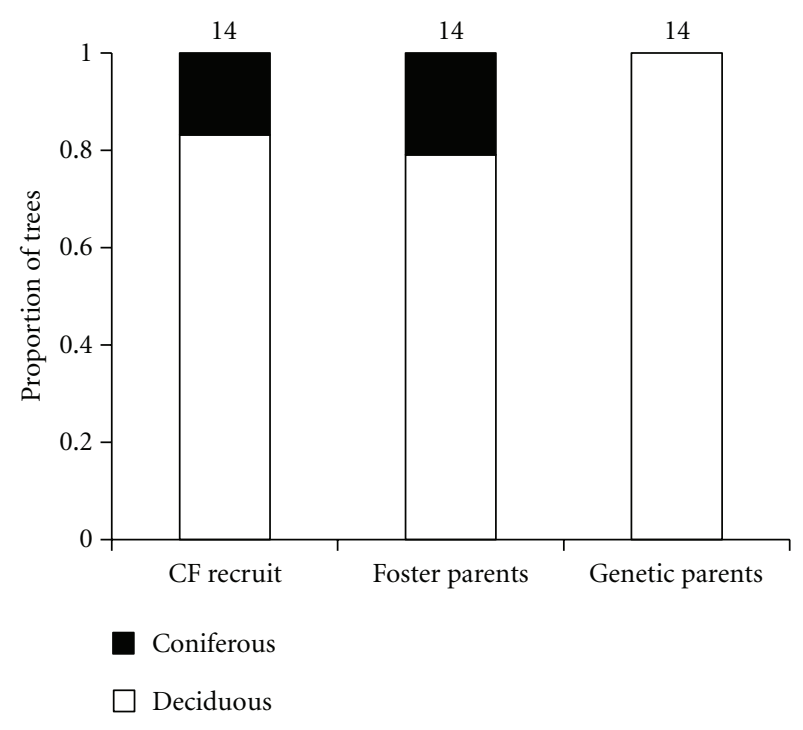

(b)

FIgure 6: Habitat composition in the breeding territories of crossfostered yearling pied (a) and collared flycatchers (b) as compared to the breeding territories of their foster parents and genetic parents on Öland, Sweden, 2002-2009. Both pied and collared flycatcher recruits returned to breed in a habitat different from their genetic parents. Only recruits that were swapped between different nest-box areas are included in this comparison, sample sizes are given above the bars.

to reflect the fact that pied flycatchers are having problems establishing territories in areas inhabited by collared flycatchers [39]. Another potential source contributing to the biased pattern of recruitment might be that collared flycatcher nestlings sharing nests with pied flycatcher nestlings have a competitive advantage in achieving food from the parents [38], which could increase the likelihood of reaching a threshold weight for successful recruitment (e.g., [29]).

Several studies indicate a poorer quality in terms of availability of the food that flycatchers feed their nestlings with in coniferous habitats as compared to deciduous habitats [35, 40, 41], and allopatric populations of pied flycatchers experience higher reproductive success in deciduous habitats $[29,42]$. Coniferous habitats are therefore unlikely to be the originally preferred habitat of pied flycatchers and in the young hybrid zone on Öland competition with collared flycatchers appears to be responsible for a rapid shift in habitat occupancy [36]. Our present study provides a mechanism by which a competition-mediated switch into a suboptimal habitat could result in a changed habitat choice through learning. We found that being reared in the initially less preferred habitat even makes collared flycatchers return to breed in this habitat as young adults. By extension, the fact that young birds develop a preference for breeding in the same type of habitat as they were reared in means that an enforced habitat shift due to competition quickly can result in divergence in habitat choice and strengthen premating isolation.

One may argue that a possible alternative explanation to our findings is that flycatchers exhibit a genetically fixed strategy to return to breed within a certain distance from their parents' nest. However, several previous findings are not compatible with this alternative view. On the Swedish mainland, pied flycatcher nestlings and their parents do not stay in close vicinity to the nest site once the offspring are fledged and the nestlings do not return to breed within the same areas as their parents [29]. On the islands of Öland and Gotland, such movements are more limited. Moreover, aviary experiments performed in the older hybrid zone in central Europe suggest that pied flycatchers have developed a preference to feed in coniferous trees [43], and these birds were caught in a coniferous habitat as the process of habitat segregation has reached a later stage in this older hybrid zone [44].

For how long do the fledglings stay in their natal area, and when does imprinting occur? Van Balen [45] studied postfledging dispersal in a Dutch pied flycatcher population and found that juvenile birds tend to stay within $600 \mathrm{~m}$ of their hatching site up to about 50 days. Berndt and Winkel [46] transferred both eggs and fledglings (about 36 days old) of pied flycatchers between areas located $250 \mathrm{~km}$ apart in northern Germany. They found that all returning birds came back to the area where they had been transferred, showing that imprinting can take place even after three weeks postfledging. A recent study on flycatchers reveals that it is possible to translocate also adult birds between environments [47]. Apart from opening up new possibilities to study the fitness consequences of breeding in different habitats, this finding also indicate that the importance of plasticity and learning in general might have been underestimated in studies of avian habitat choice. By showing that birds that have been experimentally reared in a different environment, as compared to their genetic parents, subsequently return to the area of their foster parents, our results provide additional support for the importance of early learning in habitat choice, also on a small geographical scale.

In a few cases, the birds recruiting from our experiment settled to breed relatively far away from their foster area. Although we cannot make any inferences from those few 
cases, future studies could try to pinpoint detailed differences in dispersal strategies and habitat choice in relation to, for example, population density, relative frequency of competitors, and variation in microhabitat quality. Natal conditions are likely to affect dispersal propensity in a number of ways. For example, high-quality habitats may produce more individuals prone to disperse as compared to low-quality habitats [48]. Lens and Dhondt [49] found a link between habitat condition and natal dispersal in crested tits (Parus cristatus), where individuals from higher quality habitats dispersed more readily than individuals from lowerquality habitats. Heritable differences in dispersal propensity in coupling with other behaviors (e.g., aggression) have been suggested to be especially important during natural range expansions or hybrid zone movements in birds [50]. However, as Davis and Stamps [20] point out: if dispersers have a strong innate preference for their natal habitat type, the degree of similarity between patches will influence the rate of dispersal such that dispersal into novel habitats is prohibited. On the other hand, recent bird studies indicate a strong role for habitat-related cultural transmission through early learning, for example, in the feeding strategy of great tits [51], natal dispersal of pied flycatchers [52], and habitat selection in the warbler finches of Galápagos, where females choose to breed on islands with habitats similar to their natal environment [53].

Tonnis et al. [53] found a positive correlation between genetic distances in the warbler finches of Galápagos and differences in maximum elevation among islands and concluded that habitat selection may have helped to initiate the speciation process. The genetic component of habitat preferences might be larger in more specialized populations, and speciation may occur as assortative mating evolves [24]. The effectiveness of learned habitat preferences in speciation could be due to being a one-allele mechanism [54], whereas speciation through a genetic habitat preference has been suggested to be a two-allele mechanism [24]. In other words, when habitat choice is genetically determined, genetic recombination can lead to a breakdown of the associations between the alleles underlying habitat choice and the alleles underlying ecological adaptation, whereas this is not a problem with a learned habitat preference. Song learning is another example of a culturally transmitted trait in birds suggested to operate in a similar way [55].

In summary, we have shown that an enforced shift in breeding habitat choice can be further enhanced by early imprinting on the natal area. From a theoretical point of view, learned habitat choice might be a powerful mechanism of generating assortative mating [24]. When one species shifts breeding habitat due to interspecific competition, segregation in habitat choice will increase (and premating isolation as a side effect) when recruitment into the alternative environment exceeds recruitment into the originally preferred environment due to learning (i.e., imprinting on the natal environment). Thus, learned habitat choice can play an important role both in enhancing reproductive isolation and in facilitating regional coexistence at secondary contact between diverging populations.

\section{Acknowledgments}

The authors would like to thank Zoologiska stiftelsen (NV), the Swedish Research Council (AQ), and the European Research Foundation (AQ) for financial support.

\section{References}

[1] D. Schluter, "Ecology and the origin of species," Trends in Ecology and Evolution, vol. 16, no. 7, pp. 372-380, 2001.

[2] H. D. Rundle and P. Nosil, "Ecological speciation," Ecology Letters, vol. 8, no. 3, pp. 336-352, 2005.

[3] G. S. Van Doorn, P. Edelaar, and F. J. Weissing, "On the origin of species by natural and sexual selection," Science, vol. 326, no. 5960, pp. 1704-1707, 2009.

[4] A. M. Rice, A. Rudh, H. Ellegren, and A. Qvarnström, "A guide to the genomics of ecological speciation in natural animal populations," Ecology Letters, vol. 14, no. 1, pp. 9-18, 2011.

[5] W. R. Rice and G. W. Salt, "The evolution of reproductive isolation as a correlated character under sympatric conditions: experimental evidence," Evolution, vol. 44, no. 5, pp. 11401152, 1990.

[6] W. R. Rice, "Disruptive selection on habitat preference and the evolution of reproductive isolation: a simulation study," Evolution, vol. 38, no. 6, pp. 1251-1260, 1984.

[7] P. A. Johnson, F. C. Hoppensteadt, J. J. Smith, and G. L. Bush, "Conditions for sympatric speciation: a diploid model incorporating habitat fidelity and non-habitat assortative mating," Evolutionary Ecology, vol. 10, no. 2, pp. 187-205, 1996.

[8] T. J. Kawecki, "Sympatric speciation driven by beneficial mutations," Proceedings of the Royal Society B, vol. 263, no. 1376, pp. 1515-1520, 1996.

[9] T. J. Kawecki, "Sympatric speciation via habitat specialization driven by deleterious mutations," Evolution, vol. 51, no. 6, pp. 1751-1763, 1997.

[10] A. S. Kondrashov and F. A. Kondrashov, "Interactions among quantitative traits in the course of sympatric speciation," Nature, vol. 400, no. 6742, pp. 351-354, 1999.

[11] U. Dieckmann and M. Doebeli, "On the origin of species by sympatric speciation,” Nature, vol. 400, no. 6742, pp. 354-357, 1999.

[12] J. D. Fry, "Multilocus models of sympatric speciation: bush versus rice versus felsenstein," Evolution, vol. 57, no. 8, pp. 1735-1746, 2003.

[13] E. Mayr, Systematics and the Origin of Species, Columbia University Press, New York, NY, USA, 1942.

[14] T. Dobzhansky, Genetics and the Origin of Species, Columbia University Press, New York, NY, USA, 3rd edition, 1951.

[15] J. A. Coyne and H. A. Orr, Speciation, Sinauer Associates, Massachusetts, Mass, USA, 2004.

[16] X. Thibert-Plante and A. P. Hendry, "The consequences of phenotypic plasticity for ecological speciation," Journal of Evolutionary Biology, vol. 24, no. 2, pp. 326-342, 2011.

[17] T. D. Price, A. Qvarnström, and D. E. Irwin, "The role of phenotypic plasticity in driving genetic evolution," Proceedings of the Royal Society B, vol. 270, no. 1523, pp. 1433-1440, 2003.

[18] M. J. West-Eberhard, Developmental Plasticity and Evolution, Oxford University Press, New York, NY, USA, 2003.

[19] M. J. West-Eberhard, "Developmental plasticity and the origin of species differences," Proceedings of the National Academy of Sciences of the United States of America, vol. 102, no. 1, pp. 6543-6549, 2005. 
[20] J. M. Davis and J. A. Stamps, "The effect of natal experience on habitat preferences," Trends in Ecology and Evolution, vol. 19, no. 8, pp. 411-416, 2004.

[21] D. E. Irwin and T. Price, "Sexual imprinting, learning and speciation," Heredity, vol. 82, no. 4, pp. 347-354, 1999.

[22] W. H. Thorpe, "The evolutionary significance of habitat selection," Journal of Animal Ecology, vol. 14, pp. 67-70, 1945.

[23] J. Maynard Smith, "Sympatric speciation," American Naturalist, vol. 100, pp. 637-650, 1966.

[24] J. B. Beltman and J. A. J. Metz, "Speciation: more likely through a genetic or through a learned habitat preference?" Proceedings of the Royal Society B, vol. 272, no. 1571, pp. 1455$1463,2005$.

[25] T. Slagsvold and K. L. Wiebe, "Social learning in birds and its role in shaping a foraging niche," Philosophical transactions of the Royal Society of London Series B, vol. 366, no. 1567, pp. 969-977, 2011.

[26] A. Qvarnström, A. M. Rice, and H. Ellegren, "Speciation in Ficedula flycatchers," Philosophical Transactions of the Royal Society B, vol. 365, no. 1547, pp. 1841-1852, 2010.

[27] G. P. Sætre, T. Borge, J. Lindell et al., "Speciation, introgressive hybridization and nonlinear rate of molecular evolution in flycatchers," Molecular Ecology, vol. 10, no. 3, pp. 737-749, 2001.

[28] T. Veen, N. Svedin, J. T. Forsman et al., "Does migration of hybrids contribute to post-zygotic isolation in flycatchers?" Proceedings of the Royal Society B, vol. 274, no. 1610, pp. 707$712,2007$.

[29] A. Lundberg and R. V. Alatalo, The Pied Flycatcher, Poyser, London, UK, 1992.

[30] T. Pärt and A. Qvarnström, "Badge size in collared flycatchers predicts outcome of male competition over territories," Animal Behaviour, vol. 54, no. 4, pp. 893-899, 1997.

[31] A. Qvarnstrom, "Experimentally increased badge size increases male competition and reduces male parental care in the collared flycatcher," Proceedings of the Royal Society B, vol. 264, no. 1385, pp. 1225-1231, 1997.

[32] A. Qvarnström, C. Wiley, N. Svedin, and N. Vallin, "Lifehistory divergence facilitates regional coexistence of competing Ficedula flycatchers," Ecology, vol. 90, no. 7, pp. 1948-1957, 2009.

[33] C. Wiley, N. Fogelberg, S. A. Sæther et al., "Direct benefits and costs for hybridizing Ficedula flycatchers," Journal of Evolutionary Biology, vol. 20, no. 3, pp. 854-864, 2007.

[34] A. Qvarnström, N. Svedin, C. Wiley, T. Veen, and L. Gustafsson, "Cross-fostering reveals seasonal changes in the relative fitness of two competing species of flycatchers," Biology Letters, vol. 1, no. 1, pp. 68-71, 2005.

[35] T. Veen, B. C. Sheldon, F. J. Weissing, M. E. Visser, A. Qvarnström, and G. P. Sætre, "Temporal differences in food abundance promote coexistence between two congeneric passerines," Oecologia, vol. 162, no. 4, pp. 873-884, 2010.

[36] N. Vallin, A. M. Rice, R. I. Bailey, A. Husby, and A. Qvarnström, "Positive feedback between ecological and reproductive character displacement in a young avian hybrid zone," Evolution. In press.

[37] N. Svedin, C. Wiley, T. Veen, L. Gustafsson, and A. Qvarnström, "Natural and sexual selection against hybrid flycatchers," Proceedings of the Royal Society B, vol. 275, no. 1635, pp. 735-744, 2008.

[38] A. Qvarnström, J. V. Kehlenbeck, C. Wiley, N. Svedin, and S. A. Sæther, "Species divergence in offspring begging intensity: difference in need or manipulation of parents?" Proceedings of the Royal Society B, vol. 274, no. 1612, pp. 1003-1008, 2007.
[39] N. Vallin, A. M. Rice, H. Arntsen, K. Kulma, and A. Qvarnström, "Combined effects of interspecific competition and hybridization impede local coexistence of Ficedula flycatchers," Evolutionary Ecology. In press.

[40] L. Gezelius, M. Grahn, H. Kallander, and J. Karlsson, "Habitatrelated differences in clutch size of the pied flycatcher Ficedula hypoleuca," Annales Zoologici Fennici, vol. 21, no. 3, pp. 209212, 1984.

[41] T. Eeva, S. Ruuskanen, J. P. Salminen et al., "Geographical trends in the yolk carotenoid composition of the pied flycatcher (Ficedula hypoleuca)," Oecologia, pp. 1-11, 2010.

[42] A. Jarvinen, "Clutch-size variation in the pied flycatcher Ficedula hypoleuca," Ibis, vol. 131, no. 4, pp. 572-577, 1989.

[43] P. Adamík and S. Bureš, "Experimental evidence for speciesspecific habitat preferences in two flycatcher species in their hybrid zone," Naturwissenschaften, vol. 94, no. 10, pp. 859863, 2007.

[44] G. P. Sætre, M. Král, S. Bureš, and R. A. Ims, "Dynamics of a clinal hybrid zone and a comparison with island hybrid zones of flycatchers (Ficedula hypoleuca and F. Albicollis)," Journal of Zoology, vol. 247, no. 1, pp. 53-64, 1999.

[45] J. H. Van Balen, "Observations on the post-fledging dispersal of the pied flycatcher, Ficedula hypoleuca," Ardea, vol. 67, pp. 134-137, 1979.

[46] R. Berndt and W. Winkel, "Transfer-experiments on problems of imprinting to the birthplace in the Pied Flycatcher Ficedula hypoleuca," Journal of Ornithology, vol. 120, no. 1, pp. 41-53, 1979.

[47] C. Burger and C. Both, "Translocation as a novel approach to study effects of a new breeding habitat on reproductive output in wild birds," PLoS ONE, vol. 6, no. 3, article e18143, 2011.

[48] M. F. Benard and S. J. McCauley, "Integrating across lifehistory stages: consequences of natal habitat effects on dispersal," American Naturalist, vol. 171, no. 5, pp. 553-567, 2008.

[49] L. Lens and A. A. Dhondt, "Effects of habitat fragmentation on the timing of crested tit Parus cristatus natal dispersal," Ibis, vol. 136, no. 2, pp. 147-152, 1994.

[50] R. A. Duckworth and L. E. B. Kruuk, "Evolution of genetic integration between dispersal and colonization ability in a bird," Evolution, vol. 63, no. 4, pp. 968-977, 2009.

[51] T. Slagsvold and K. L. Wiebe, "Learning the ecological niche," Proceedings of the Royal Society B, vol. 274, no. 1606, pp. 19-23, 2007.

[52] N. Chernetsov, L. V. Sokolov, V. Kosarev et al., "Sex-related natal dispersal of Pied Flycatchers: how far away from home?" Condor, vol. 108, no. 3, pp. 711-717, 2006.

[53] B. Tonnis, P. R. Grant, B. R. Grant, and K. Petren, "Habitat selection and ecological speciation in Galápagos warbler finches (Certhidea olivacea and Certhidea fusca)," Proceedings of the Royal Society B, vol. 272, no. 1565, pp. 819-826, 2005.

[54] J. Felsenstein, "Skepticism towards Santa Rosalia, or why are there so few kinds of animals," Evolution, vol. 35, pp. 124-138, 1981.

[55] R. F. Lachlan and M. R. Servedio, "Song learning accelerates allopatric speciation,” Evolution, vol. 58, no. 9, pp. 2049-2063, 2004. 

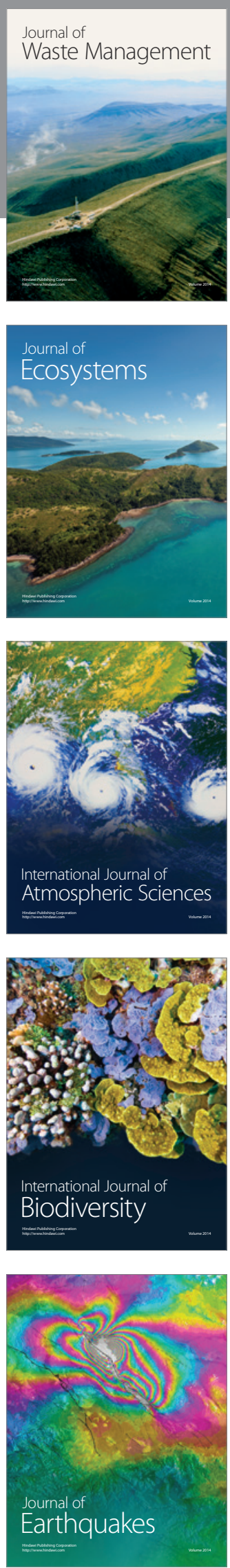
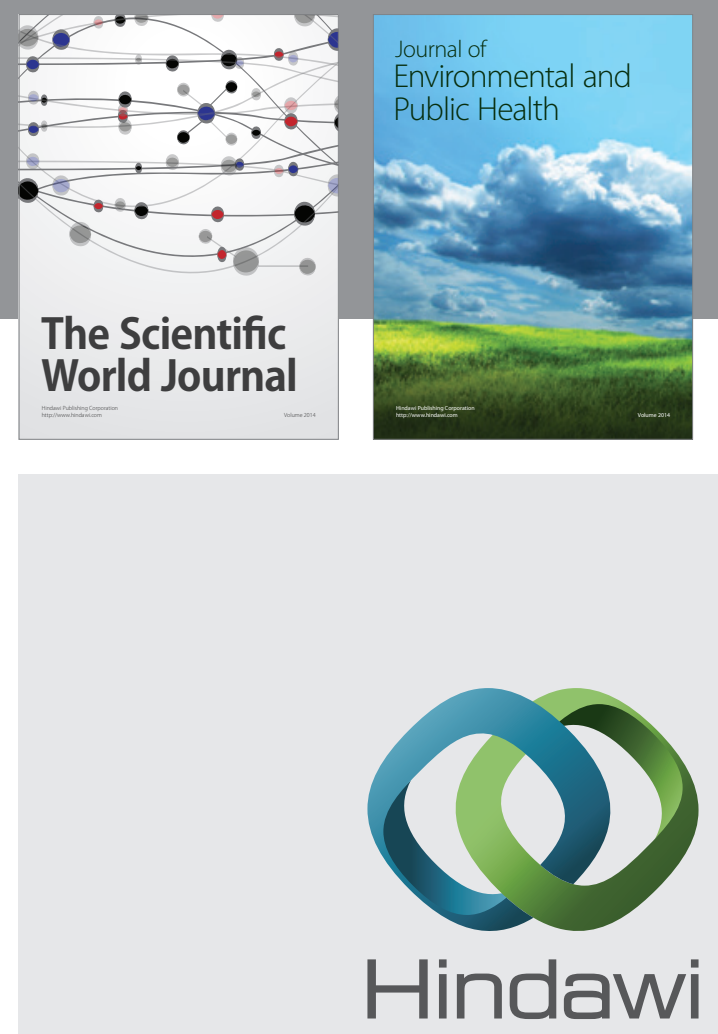

Submit your manuscripts at

http://www.hindawi.com
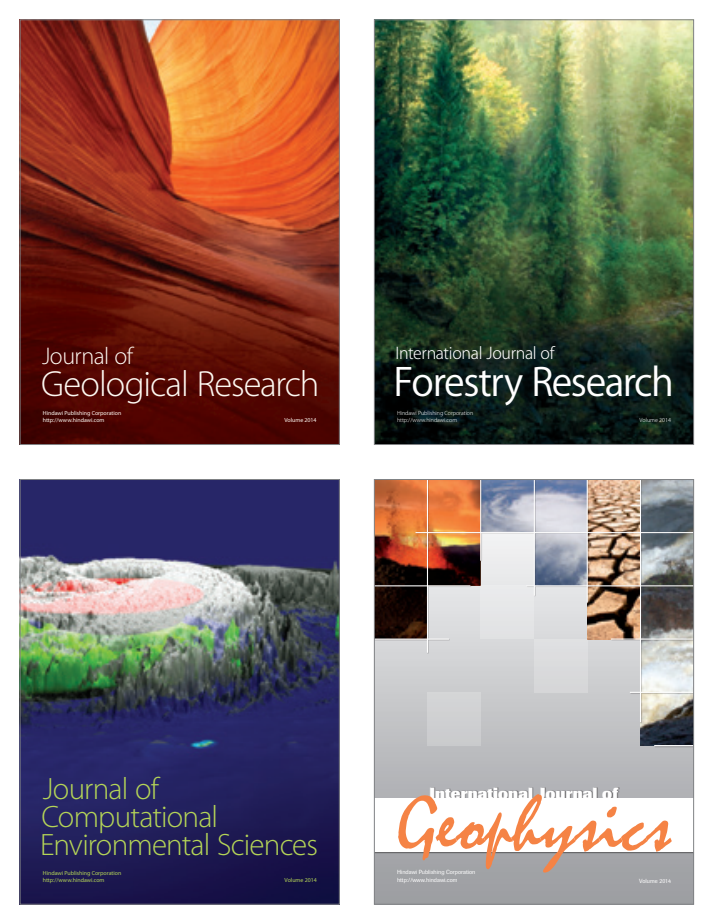
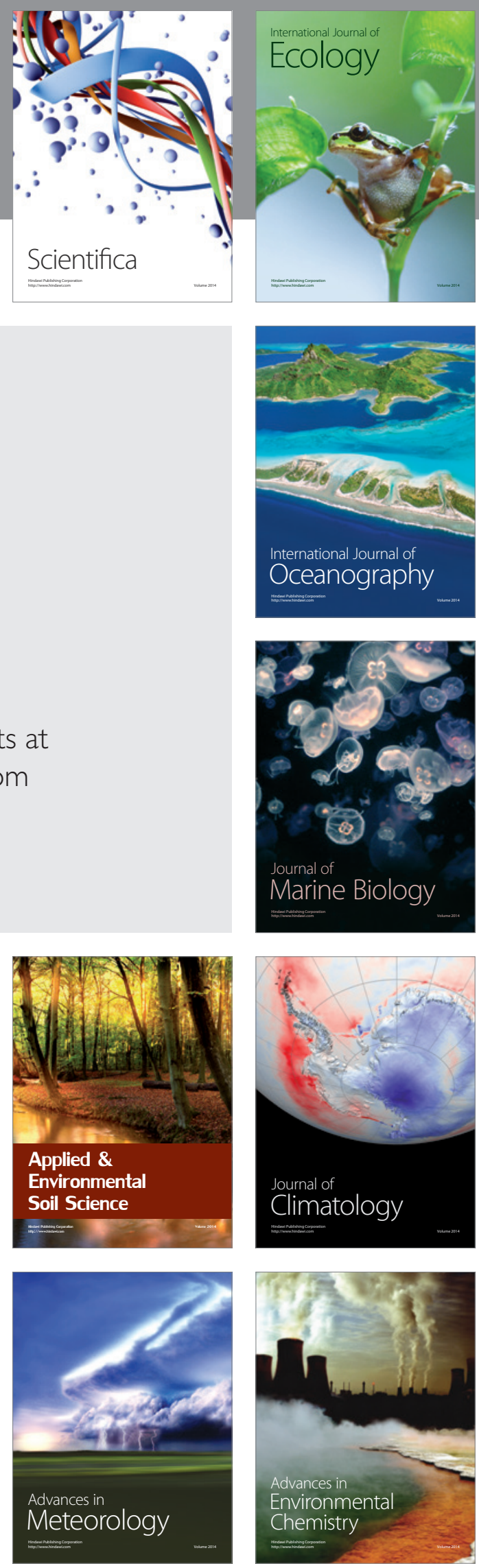